\title{
Comparison of girth weld tearing resistance obtained from Curved Wide Plate and Single Edge Notch Tensile testing
}

\author{
M.A. Verstraete*, W. De Waele, K. Van Minnebruggen, S. Hertelé \\ Soete Laboratory, Ghent University, Faculty of Engineering and Architecture, Technologiepark 903, 9052 Zwijnaarde, Belgium
}

\section{A R T I C L E I N F O}

\section{Article history:}

Received 3 September 2014

Received in revised form 4 March 2015

Accepted 23 March 2015

Available online $\mathrm{xxxx}$

\section{Keywords:}

SENT

CWP

Direct Current Potential Drop (DCPD)

Tearing resistance

\begin{abstract}
A B S T R A C T
Curved Wide Plate and Single Edge Notch Tensile tests are commonly considered for girth weld defect assessment. It is however not clear which test yields the least conservative estimate of the tearing resistance. A combined numerical-experimental procedure has been established to measure the crack extension, based on the direct current potential drop technique. This procedure appears accurate with respect to testing standards. In addition, the tearing resistance of the SENT specimens appears noticeably lower compared to wide plate specimens. This implies that SENT testing introduces conservatism in a girth weld defect assessment.
\end{abstract}

(c) 2015 Elsevier Ltd. All rights reserved.

\section{Introduction}

Gas and oil transportation pipelines are constructed by welding pipe pups of $12-18 \mathrm{~m}$ in length together through so-called girth welds. These girth welds are constructed on the installation site of the pipelines and are therefore prone to defects. To assess the allowable defect dimension of such girth weld defects, an experimental evaluation of the material's performance remains vital, in particular for demanding (e.g. strain-based) applications [1,2]. Two commonly considered tests are the small scale Single-Edge Notched Tensile (SENT) test and the medium scale Curved Wide Plate (CWP) test [3-7] (see also Fig. 1). The first is primarily considered for the evaluation of the tearing resistance that serves as input for analytical assessment procedures; the latter straightforwardly links to the tensile strain capacity after applying a pressure correction factor $[8,9]$. Additionally, CWP testing potentially allows to evaluate the tearing resistance.

Although multiple specimen procedures are described in literature (e.g. DNV RP-F108 [10]), single specimen techniques for evaluating a material's tearing resistance are preferred since these reduce the required amount of test material. The single specimen approach requires an accurate evaluation of the crack growth and crack tip opening displacement (CTOD). With respect to crack growth, recent studies mostly focus on the unloading compliance method [5,6,11]. However, there are several known issues in applying this method, e.g. the need for extensive elastic-plastic finite element simulations when it comes to data obtained from CWP tests [5]. Alternatively, the Direct Current Potential Drop (DCPD) method can be applied. A constant current is thereby applied through the cracked section. Subsequently, the measured potential drop across the crack is related to the crack size, through the use of either analytical equations or finite element simulations. For the evaluation of the crack tip opening displacement (CTOD), the double clip gauge method has been applied for both the medium and small scale tests $[12,13]$.

\footnotetext{
* Corresponding author.

E-mail address: Matthias.Verstraete@UGent.be (M.A. Verstraete).
} 


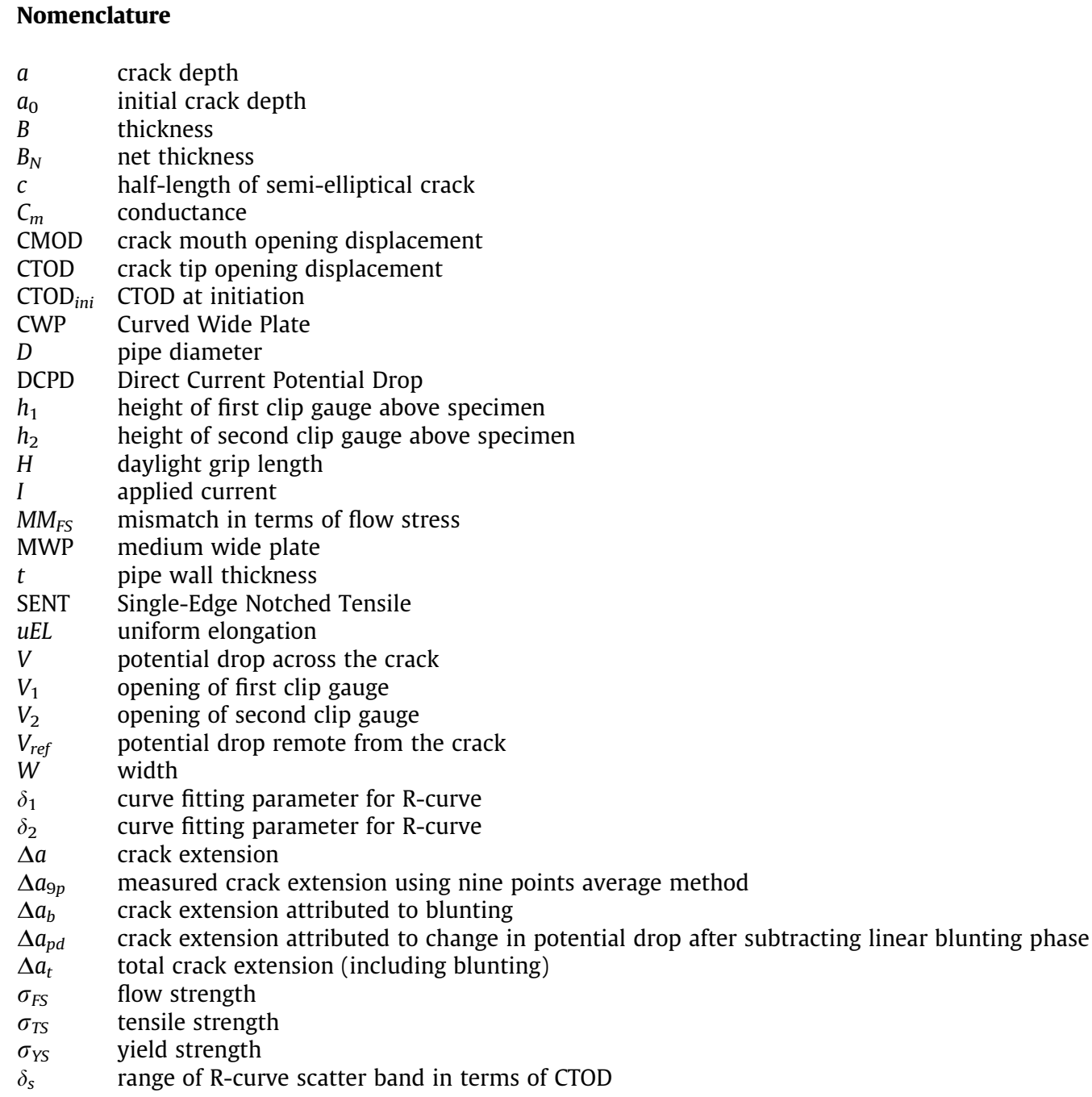

Different parameters are known to impact the tearing resistance. The constraint difference that originates from a different crack tip stress state is one of the major parameters controlling the tearing resistance $[14,15]$. To reduce the conservatism involved in assessing girth weld defects, it is important to minimize the difference in constraint between the test specimen and the final application (i.e. pressurized pipelines). Both the SENT and CWP tests are known to be (limitedly) conservative compared to (pressurized) pipes [7,16,17]. However, there is an ongoing debate on the constraint difference between both tests $[18,19]$.

Within the framework of this paper, the tearing resistance is evaluated using both SENT and CWP tests. The DCPD method has been selected to evaluate the crack extension. Based on the resulting tearing resistance curves, the constraint difference between both specimens is assessed.

\section{Materials and methods}

\subsection{Test specimens and conditions}

In this section a description is provided of the performed SENT and CWP tests. For both specimen types, the notch has been introduced through saw-cutting with a metallic blade, resulting in an initial root radius of $0.075 \mathrm{~mm}$. Fatigue precracking has not been applied, which additionally yielded the advantage of a precisely controllable initial defect dimension and minimal variability between theoretically equal (i.e. identical relative crack depth) specimens. The latter is particularly relevant as the focus of this paper is primarily on the evaluation of the accuracy of the measurement technique. For the welded specimens, the initial notch has been located at the weld metal center (WMC) line. Since the relative crack depth 


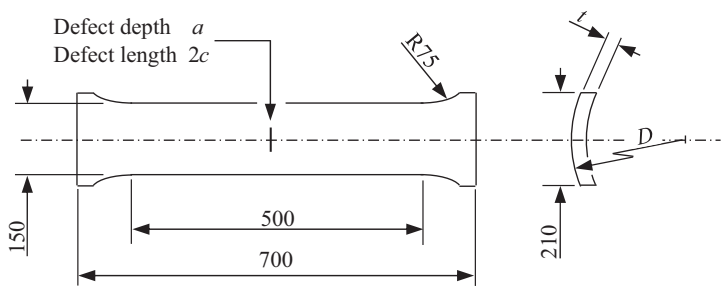

(a)
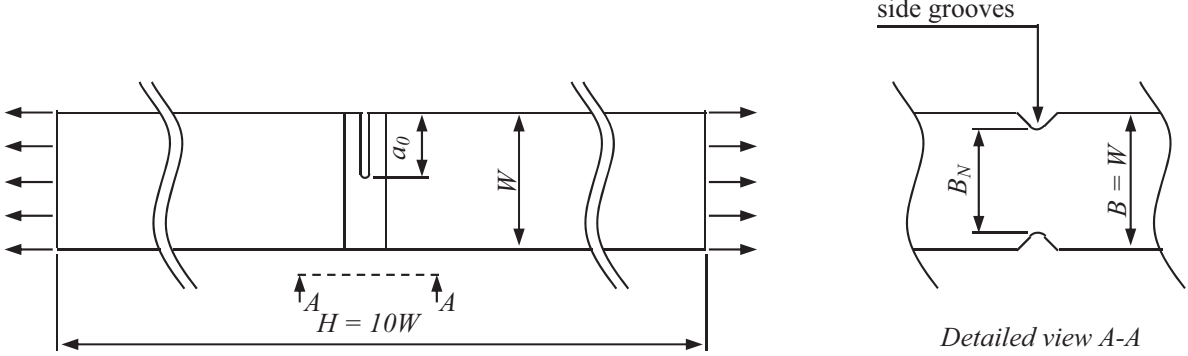

Detailed view A-A

(b)

Fig. 1. Schematic overview of tested MWP (a) and SENT (b) specimens.

is known to significantly alter the constraint both in CWP and SENT tests [17,20,21], specimens of nominally equal crack depth are compared.

Focusing on the medium scale tests, so-called medium wide plate (MWP) specimens with a reduced width of $150 \mathrm{~mm}$ were selected over the traditionally considered $300 \mathrm{~mm}$ wide Curved Wide Plate (CWP) specimens. These specimens fit Soete Laboratory's $2500 \mathrm{kN}$ test rig, which provides an excellent visibility of the test specimen. The latter is required for the application of full field deformation measurements [22,23], which were performed during this test program for reasons that are outside the scope of this paper. The initial notch has a near to semi-elliptical shape. An overview of the specimen dimensions is provided in Fig. $1 \mathrm{a}$. The parameter $a$ represents the crack depth, $2 c$ represents the crack length. To enable mounting of the specimen in the test rig, it is welded to loading lugs. To lower the stress in the connecting weld, the specimen gradually widens at the end. The wider aspects are referred to as the specimen's shoulders in the remainder of this paper. This specimen was extracted from the parent pipe through a flame cutting process. The specimen is loaded in tension with a constant displacement rate of $0.01 \mathrm{~mm} / \mathrm{sec}$. During this test, the applied load and full field surface deformation is recorded. The latter is evaluated using the Digital Image Correlation (DIC) technique and allows to evaluate the remote strains in both base plates, as described by Hertelé et al. [5,23].

The SENT test results presented in this paper are obtained from specimens with a square cross section $(B / W=1)$ that have been machined from the parent pipe. Specimen dimensions are illustrated in Fig. 1b. The daylight grip length $(H)$ equals $10 \mathrm{~W}$, as also proposed by Shen et al. [6]. To promote a uniform crack extension, the specimens are side grooved, resulting in a total thickness reduction of $15 \%\left(B_{N}=0.85 \mathrm{~W}\right)$ as advised by Shen et al. [24]. These side grooves have an opening angle less than $90^{\circ}$ and a root radius of $0.5 \pm 0.2 \mathrm{~mm}$. The specimens are clamped using hydraulic grips mounted in a $150 \mathrm{kN}$ tensile test rig and loaded under displacement control, with a loading rate of $0.01 \mathrm{~mm} / \mathrm{sec}$. The specimens are loaded beyond maximum force in the load-displacement curve. To obtain a sufficient amount of ductile crack extension, the tests are continued until the force drops back to $80 \%$ of the maximum recorded value. For a detailed description of the SENT testing procedure, the reader is referred to [25].

\subsection{Test material}

Five sets of SENT and MWP tests are covered in this paper. Each set consists of at least three (mostly four) SENT specimens and one MWP specimen. In addition, traditional tensile test specimens are extracted to characterize the base and weld metal's stress-strain properties. The former are obtained from full thickness specimens. The latter are obtained from all weld metal round bar specimens extracted at mid-thickness. These subsequently allow evaluating the weld metal mismatch, defined in terms of flow strength $\left(M M_{F S}\right)$ [26]. This mismatch is defined by the following equation, based on the flow strength of the base $\left(\sigma_{F S, B M}\right)$ and weld metal $\left(\sigma_{F S, W M}\right)$.

$$
M M_{F S}=\frac{\sigma_{F S, W M}-\sigma_{F S, B M}}{\sigma_{F S, B M}}
$$


Given the potential variation of the material properties as function of the extraction position [27-29], the SENT specimens are extracted adjacent to the MWP specimens. An overview of the extraction position for each test specimen is provided in a fold out cutting plan (including four SENT specimens - Fig. 2).

The materials considered in this paper are listed in Table 1. Remark that set 1 was obtained from a flat, non-welded plate. The other four sets were extracted from pipeline girth welds, with varying mismatch levels (expressed in terms of flow strength [30]) and initial notch sizes. The materials contained in set 2 and 3 are obtained from the same girth weld. This GMAW weld was realized in the 5G vertical ascendant position. The specimens were extracted from a different position in the circumferential direction (o'clock position), as denoted in Fig. 3 whereby the 12 o'clock position corresponds to the onset of the welding process. Each set of SENT specimens (e.g. SENT 2a) consists of at least three specimens, allowing to determine an average tearing resistance curve and scatter band. The average curve is described by an exponential curve with two fitting parameters $\delta_{1}$ and $\delta_{2}$.

$$
\mathrm{CTOD}=\delta_{1}(\Delta a)^{\delta_{2}}
$$

In the above equation, the fitting parameters are determined using a least-squares curve fitting algorithm considering the data points contained between the $0.15 \mathrm{~mm}$ and $1.50 \mathrm{~mm}$ offset lines, as described for SENB specimens in ASTM E1820 [31]. The width of the scatter band, $\delta_{s}$, is determined from the $95 \%$ confidence interval considering the same reduced set of data points [25].

\subsection{DCPD measurements}

For the DCPD technique, the selected current source preferably has a low ripple and noise (typically smaller than $0.01 \%$ relative to the applied current). For the SENT tests, a constant applied current of $25 \mathrm{~A}$ enabled accurate voltage drop measurements with a nano volt meter (Agilent type 34420A, Santa Clara, California, USA). For the MWP tests, the current magnitude has been raised to $150 \mathrm{~A}$ to compensate for the increased cross section. Notwithstanding the supplied current is direct, the potential drop across the crack may still fluctuate in the absence of crack growth. The reason for these fluctuations is twofold. First, the current flowing through the specimen might not be constant, e.g. as a result of changing current leakage through the grips of the test rig. Second, the material's electrical conductance is strongly temperature-dependent. As a result, slight temperature changes influence the measured potential drop. To overcome these issues, a two-probe technique is adopted in this paper [32-34]. To this end, the potential drop is measured at two locations. The first measurement is evidently performed across the crack, and is referred to as $V$. The second measurement, referred to as the reference measurement $V_{r e f}$, is performed remote from the crack. The voltage $V_{r e f}$ is independent of the crack extension, but captures the abovementioned parasitic effects of temperature variations and current leakage. By subsequently normalizing the potential drop across the crack by this reference potential, $V / V_{\text {ref, }}$ a measurement is obtained that is independent of temperature and current magnitude.

Fracture toughness testing of ductile materials involves the formation of plastically deforming areas around the crack tip. This plasticity influences the measured potential drop across the crack [35,36]. As described in literature, a three-phase evolution of the potential drop is typically observed as function of the crack mouth opening displacement (CMOD) (Fig. 4) [37-39].

During the first phase an increase of the potential drop is often observed. This for instance results from the separation of initially contacted crack faces or the elimination of contact due to the presence of electrically conductive debris. During the second phase, a linear increase of the potential drop as a function of the CMOD is observed. This is attributed to plasticity effects in the defect ligament. These plasticity effects can at this point be related to crack tip blunting. Hence, this linear trend is referred to as the blunting line. During the third phase a progressive increase of the potential drop is observed. At this point, ductile crack extension is assumed to occur. The amount of potential drop attributed to ductile crack extension equals

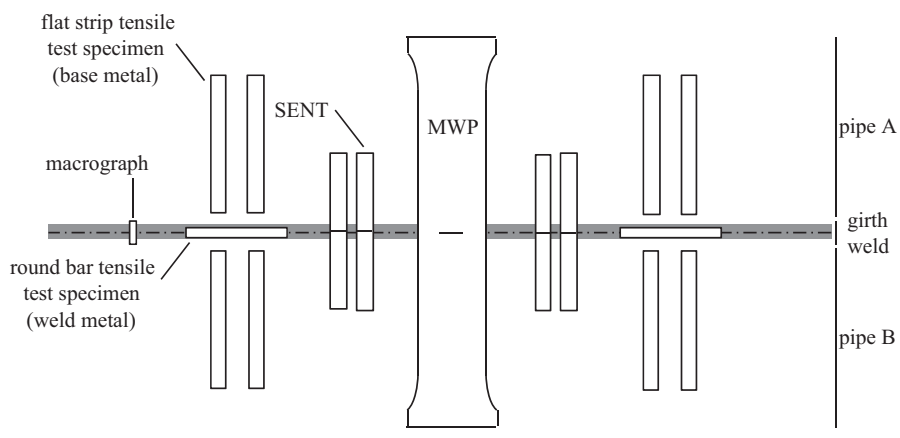

Fig. 2. Example cutting plan. 
Table 1

Tested materials.

\begin{tabular}{|c|c|c|c|c|c|c|}
\hline Set & & 1 & 2 & 3 & 4 & 5 \\
\hline \multicolumn{7}{|l|}{ MWP specifications } \\
\hline$a_{0}$ & $(\mathrm{~mm})$ & 3.00 & 4.00 & 4.00 & 5.25 & 5.25 \\
\hline $2 c$ & $(\mathrm{~mm})$ & 60 & 40 & 40 & 50 & 50 \\
\hline$D$ & $(\mathrm{~mm})$ & $\infty$ & 1219 & 1219 & 1219 & 1219 \\
\hline$t$ & $(\mathrm{~mm})$ & 15.0 & 13.7 & 13.7 & 17.0 & 17.0 \\
\hline$a_{0} / t$ & $(-)$ & 0.20 & 0.29 & 0.29 & 0.31 & 0.31 \\
\hline \multicolumn{7}{|l|}{ SENT specifications } \\
\hline$a_{0}$ & $(\mathrm{~mm})$ & 3.00 & 3.25 & 3.25 & 4.20 & 4.20 \\
\hline$W(=B)$ & $(\mathrm{mm})$ & 14.0 & 11.5 & 11.5 & 14.0 & 14.0 \\
\hline $\mathrm{H}$ & $(\mathrm{mm})$ & 140 & 115 & 115 & 140 & 140 \\
\hline$a_{0} / W$ & $(-)$ & 0.21 & 0.28 & 0.28 & 0.30 & 0.30 \\
\hline Notch location & $(-)$ & Base metal & WMC root & WMC root & WMC root & WMC root \\
\hline API-5L Grade & $(-)$ & X65 & $\mathrm{X} 70$ & X70 & $\mathrm{X} 80$ & $\mathrm{X} 80$ \\
\hline$\sigma_{Y S, B M}$ & (MPa) & 441 & 561 & 572 & 601 & 613 \\
\hline$\sigma_{T S, B M}$ & (MPa) & 539 & 621 & 625 & 675 & 676 \\
\hline$u E L_{B M}$ & $(\%)$ & 16.9 & 9.7 & 8.0 & 8.2 & 11.1 \\
\hline$\sigma_{Y S, W M}$ & (MPa) & - & 597 & 563 & 666 & 625 \\
\hline$\sigma_{T S, W M}$ & (MPa) & - & 657 & 633 & 710 & 667 \\
\hline$u E L_{W M}$ & $(\%)$ & - & 8.4 & 9.7 & 11.3 & 12.3 \\
\hline Weld strength mismatch $M M_{F S}$ & $(\%)$ & - & +6 & 0 & +8 & 0 \\
\hline
\end{tabular}

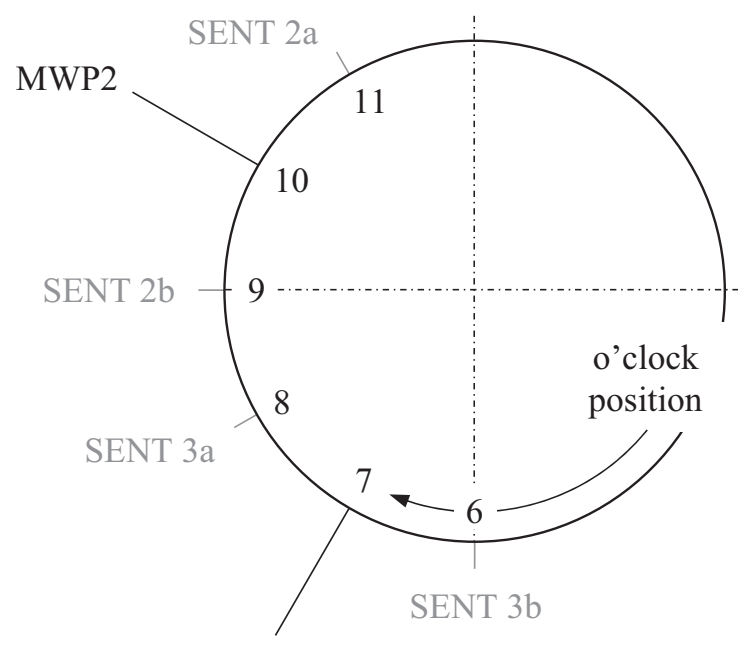

MWP3

Fig. 3. Overview of extraction position for SENT and MWP specimen contained in set 2 and 3, sampling different o'clock positions.

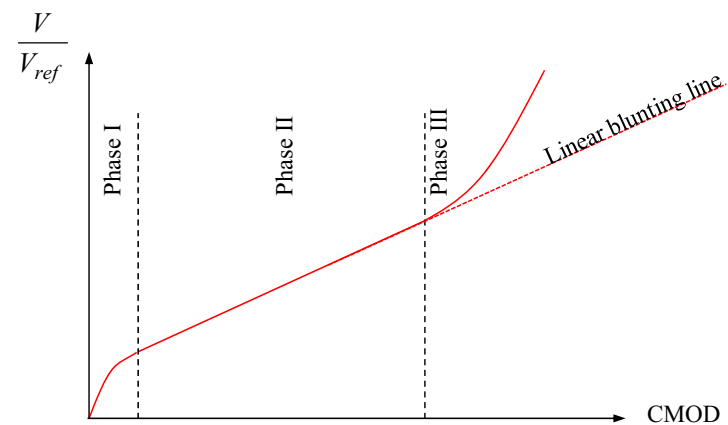

Fig. 4. Characteristic evolution of normalized potential drop as function of CMOD. 
the difference between the blunting line and the actually measured signal. Note that during this phase crack tip blunting no longer takes place, but the plasticity around the crack still increases.

To facilitate the potential drop measurements, different electrical connections to the specimen are required. First, to enable the current throughput, in- and output pins are spot-welded onto the specimen. The position of these pins relative to the cracked ligament is an important parameter. It is advisable to have a zone with a uniform potential field in the specimen. As such, the potential drop across the crack becomes independent of the current pin positions. Using finite element simulations, as described in the following section, an optimum pin position was determined for both MWP and SENT specimens [40]. For the SENT specimens, the current pins are consequently located at a distance $4 \mathrm{~W}$ from the cracked ligament (Fig. 5). For MWP specimens a uniform potential field is obtained if the current in- and output pins are located in the specimen's shoulder section.

Second, the reference probes are bolted onto the specimen. These probes are preferably located in a zone that does not deform plastically. In addition, the potential drop in this zone should not be influenced by ductile crack extension. For the SENT specimens, an extensive set of finite element simulations in combination with full field deformation measurements pointed out that these reference probes are preferably placed at twice the specimen width $(2 W)$ from the cracked ligament. Accordingly, the reference probes are in this case positioned at a distance $2 W$ and $3 W$ from the crack (Fig. 5). For the MWP specimens, the reference probes are placed adjacent to the current input and output pins in an extended shoulder section, remote from any plastic deformation (Fig. 6).

Third, the position of the probes measuring the potential drop across the crack is determined. The requirements for their position are contrasting. On one hand, increasing the distance between the crack and the probe increases the magnitude of the measured signal and hence improves the measurability. On the other hand, if these probes are positioned closer to the crack, a larger change of the measured signal per unit crack extension is obtained. In this paper, a distance of $4.5 \mathrm{~mm}$ between the crack plane and the voltage probe is selected as this has been checked to balance both requirements.

\subsection{Crack growth evaluation}

Following the measurement of the potential drop, a transfer function is required to determine the crack growth from the obtained signal. To that extent, both analytical formulae and finite element simulations can be considered. In literature, analytical formulae for converting the measured potential drop to a physical crack length are only available for SENT specimens. In 1965, Johnson [41] published an analytical equation for the evaluation of crack sizes from direct current potential drop readings. This equation assumes a uniform current field remote from the cracked ligament. Notwithstanding being originally developed for center-cracked tension (CCT) specimens, this equation can also be considered for SENT and SENB specimens. This results in Eq. (2), relating the potential drop for the actual crack depth $(V(a))$ to the potential drop for the initial crack depth $\left(V\left(a_{0}\right)\right)[42]$.

$$
\frac{V(a)}{V\left(a_{0}\right)}=\frac{\cosh ^{-1}\left(\frac{\cosh (9 \pi / 4 W)}{\cos (\pi a / 2 W)}\right)}{\cosh ^{-1}\left(\frac{\cosh (9 \pi / 4 W)}{\cos \left(\pi a_{0} / 2 W\right)}\right)}
$$

Remark that evaluating the potential drop using the above equation does not require knowledge of the material's conductance, nor does it depend on the applied current. Only the specimen's geometry and the position of the measurement probes influence the predicted crack extension.

In the absence of analytical equations, static electrical finite element simulations serve as an alternative to evaluate the potential drop across the crack as function of the crack size. Therefore, a finite element model has been developed for both

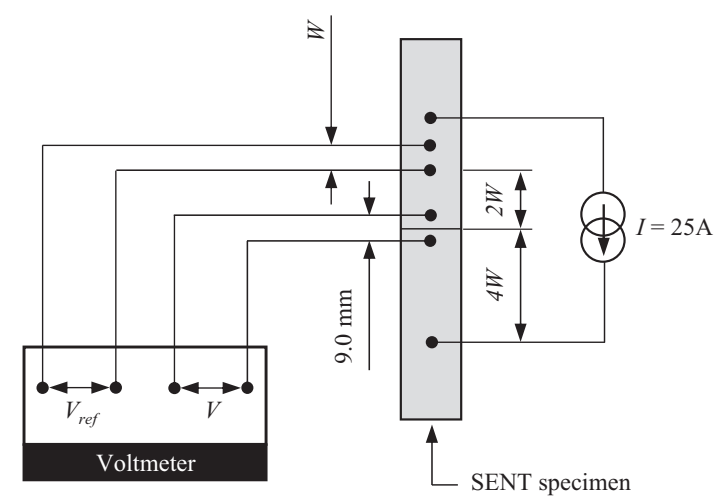

Fig. 5. Overview of voltage probe and current pin locations in SENT specimen considered in this paper. 


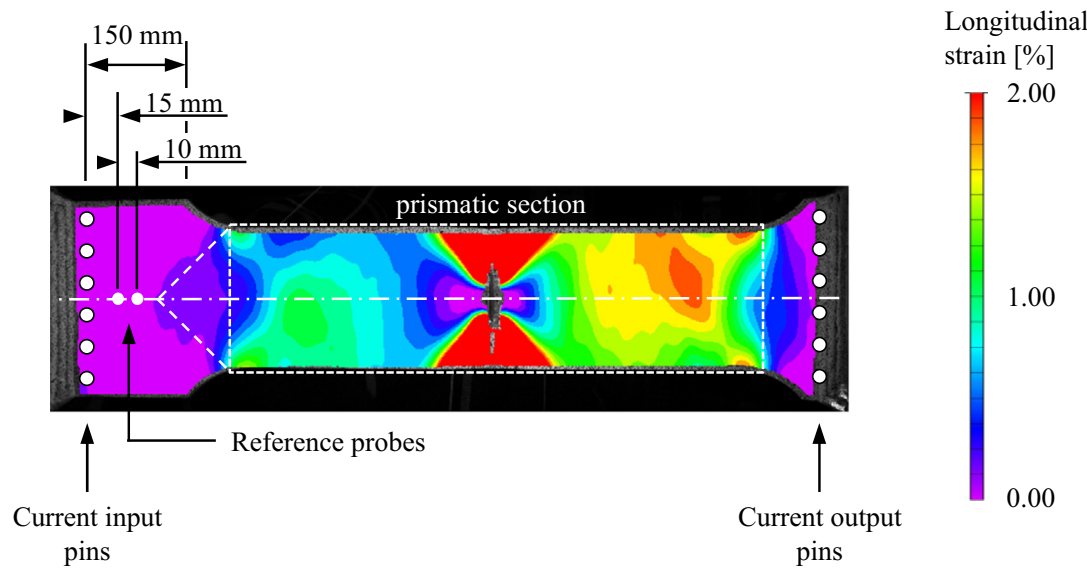

Fig. 6. Modified MWP dimensions to position the reference probes in a zone that is not plastically deforming. Strain distribution obtained through digital image correlation after failure of the specimen (beyond point of maximum force).

SENT and MWP specimens using a coupled thermal-electric model in ABAQUS ${ }^{\mathrm{TM}}$ version 6.11. These models consist of linear brick elements with reduced integration scheme (ABAQUS ${ }^{\mathrm{TM}}$ type DC3D8E). A mesh convergence study hereby assured mesh-independent electric potential calculations, resulting in approx. 10000 and 20000 elements for the SENT and MWP model respectively. Note however that these simulations incorporate neither plastic deformation nor crack growth. A mapping approach is considered for obtaining the transfer function between potential drop and crack size. The normalized potential drop is thereby interpolated between simulated (normalized) potential drops at discrete crack depths. It is thereby assumed that crack extension solely takes place in the through-thickness direction; the crack length $2 c$ is kept constant for MWP specimens. This is a fair approximation as the experimentally observed crack extension in the pipe's circumferential direction is limited for CWP tests [43,44].

For the finite element model of a SENT specimen, symmetry is assumed along the specimen's longitudinal direction. The crack, with a constant depth $a$, is modeled as a blunted crack and is surrounded by a spider web mesh. The material properties are defined in terms of the material's conductance $\left(C_{m}\right)$. Homogeneous material properties are assumed, regardless of the presence of a weld. The model is subject to a constant current, which runs through two remotely positioned current pins (Fig. 7a). To determine the electric potential in each node, a reference potential is required. As an arbitrary choice, the center of the specimen opposite to the crack mouth is grounded (Fig. 7b).

The validity of the FEA results is checked by evaluating the potential drop across the crack at varying crack depths relative to the potential drop of a crack with $a_{0} / W=0.2$. This normalized potential drop is compared to the right hand side of the Johnson equation, Eq. (2). An excellent correspondence is observed, providing confidence in this method (Fig. 8). Second, the observed correspondence suggests that 3D effects can be neglected notwithstanding the presence of side grooves in the 3D model, as the Johnson equation has originally been developed based on 2D assumptions.

For the MWP specimens, the model considered in this study adopts the mesh of a parametric mechanical finite element model of CWP specimens developed by Hertelé et al. [45]. This model starts from a simplified geometry, which is modified by means of coordinate transformations (Fig. 9). As a result, features such as weld cap reinforcement and misalignment can be adequately described.

The defect size is controlled by two parameters, namely the defect depth, $a$, and the defect length, $2 c$. These two parameters uniquely define the assumedly semi-elliptical shape of the crack. Analogous to the SENT model, the material properties are defined by the conductance of the material. A uniform conductance is assigned to the model, regardless of the presence of weld metal. In accordance with experimental practice, the current throughput is modeled using a discrete number of input and output pins located in the specimen's shoulders.

Both for the MWP and SENT tests, the proposed method only considers the potential drop data from crack initiation onwards. Consequently, the crack extension through crack tip blunting $\left(\Delta a_{b}\right)$ is not accounted for. Assuming a semi-circular crack extension during the blunting phase, this blunting is added after completion of the test and can be estimated from the CTOD at initiation $\left(\mathrm{CTOD}_{i n i}\right)$ [46]. The predicted total crack extension $\left(\Delta a_{t, p d}\right)$ therefore equals the sum of the crack extension predicted by the DCPD method $\left(\Delta a_{p d}\right)$ and the crack extension attributed to crack tip blunting.

$$
\begin{aligned}
& \Delta a_{b}=\mathrm{CTOD} / 2 \quad \text { CTOD } \leq \mathrm{CTOD}_{i n i} / 2 \\
& \Delta a_{b}=\mathrm{CTOD}_{i n i} / 2 \quad \text { CTOD } \geq \mathrm{CTOD}_{i n i} / 2 \\
& \Delta a_{t, p d}=\Delta a_{b, p d}+\Delta a_{p d}
\end{aligned}
$$




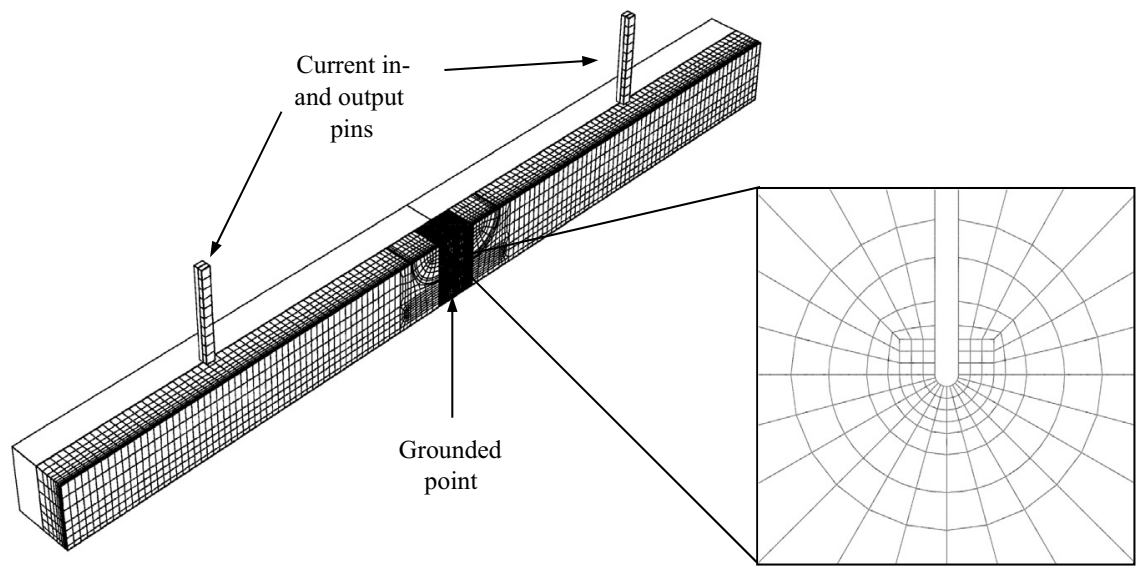

(a)

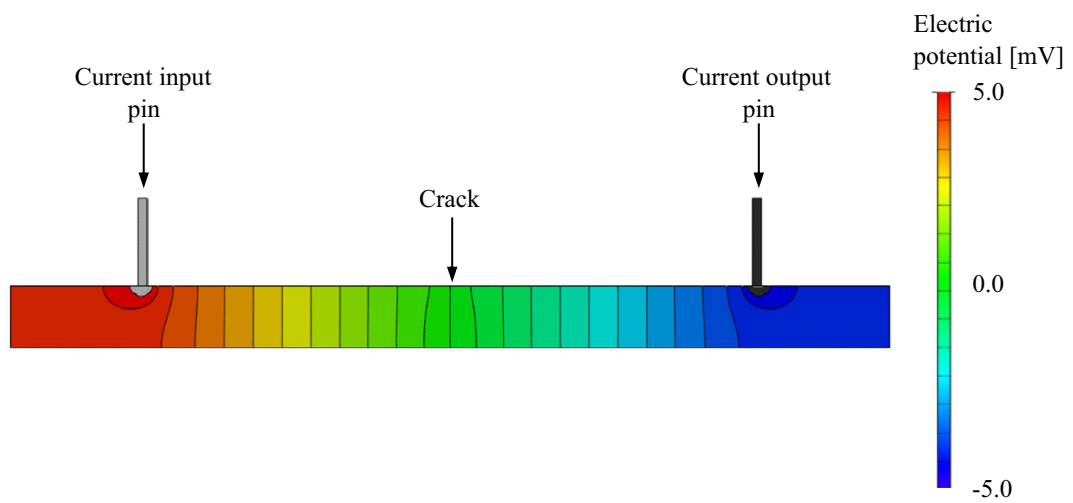

(b)

Fig. 7. Overview of 3D SENT FE model for potential drop evaluation (a) and characteristic electric potential field in the symmetry plane indicating slight non-uniformity of the electric potential field near crack and current in- and output pins (b).

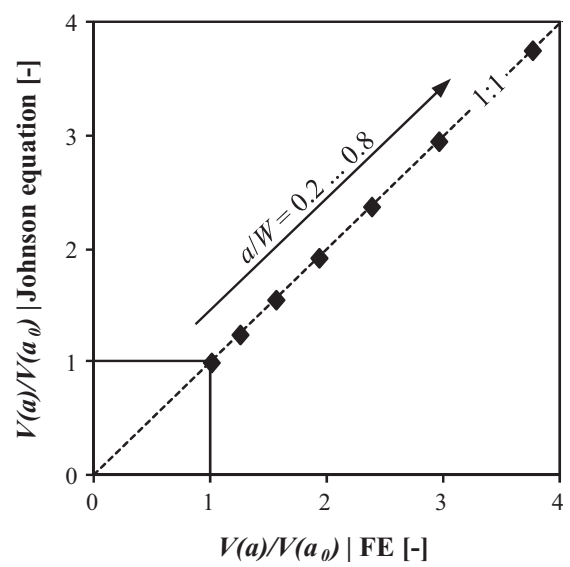

Fig. 8. Comparison of analytically calculated and FEA simulated normalized potential drop in SENT specimens.

\subsection{CTOD measurements}

For the evaluation of the crack tip opening displacement (CTOD) and crack mouth opening displacement (CMOD), the double clip gauge method is considered as discussed in a previous publication [47]. Two clip gauges are attached via knife 


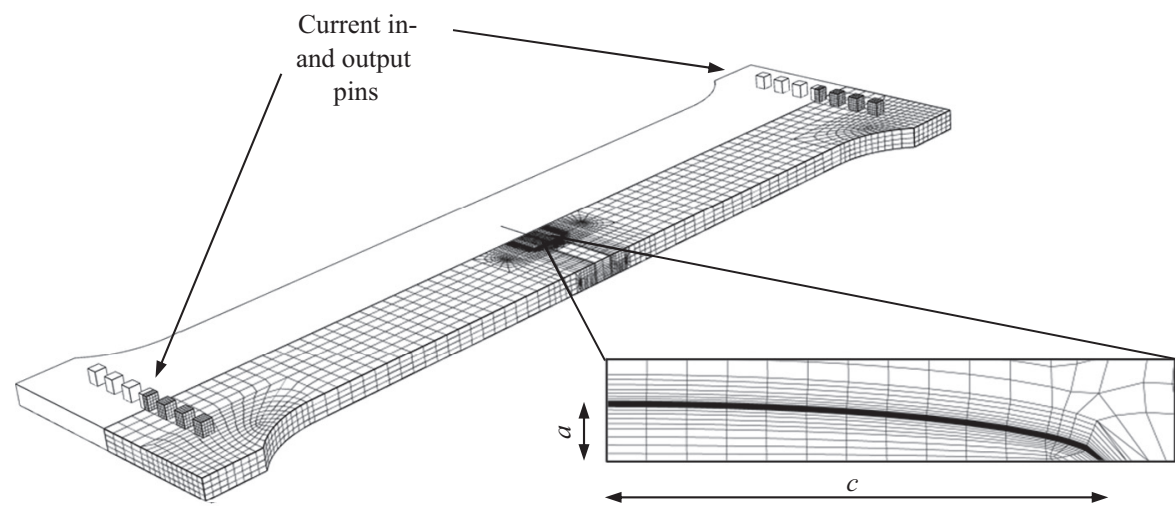

(a)

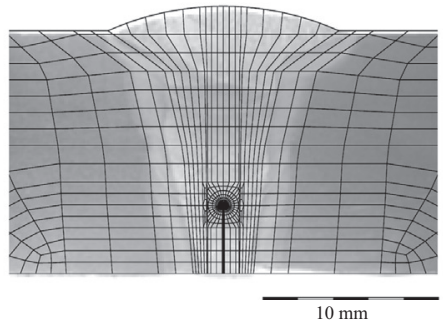

(b)

Fig. 9. Overview of finite element mesh (consisting of approx. 20000 elements) in MWP specimen with detail of semi-elliptical crack dimensions (a) and overlay plot of mesh after coordinate transformations involving weld cap reinforcement and weld profile with etched macrograph for wide plate test going with series 2 (b).

blocks to the specimen, at different heights above the crack mouth. Using triangulation, CTOD and CMOD are subsequently calculated as:

$$
\begin{aligned}
& \text { CTOD }=2 \frac{V_{2}\left(a_{0}+h_{1}\right)-V_{1}\left(a_{0}+h_{2}\right)}{\left(V_{2}-V_{1}\right)-2\left(h_{2}-h_{1}\right)} \\
& \mathrm{CMOD}=V_{1}-\frac{h_{1}}{h_{2}-h_{1}}\left(V_{2}-V_{1}\right)
\end{aligned}
$$

with (all dimensions in $\mathrm{mm}$ ):

$h_{1}, h_{2}$ mounting height of lower and upper clip gauge, respectively.

$V_{1}, V_{2}$ change in displacement using lower and upper clip gauge, respectively.

$a_{0}$ initial crack depth.

\section{Results}

\subsection{Crack extension in SENT testing}

The accuracy of the presented DCPD method is evaluated by comparing the calculated total crack extension (including blunting effect, $\left.\Delta a_{t, p d}\right)$ to the one measured using the nine point average technique $\left(\Delta a_{9 p}\right)$ after breaking up the specimens in liquid nitrogen. Subsequently, the standard deviation between both measures of crack extension is calculated. This leads to the accuracy of the DCPD method, which is defined as the width of the 95\% confidence interval. For the studied tests, this accuracy equals $\pm 0.26 \mathrm{~mm}( \pm 10.8 \%)$. Note that this value is significantly lower than the accuracy required by the ASTM E1820 requirements for SENB testing, which states the difference should be limited to $15 \%$ of the average measured crack extension. This requirement is met for the current set of tests, as indicated by the dotted line in Fig. 10a.

For some cases, however, the potential drop method clearly results in an underestimation of the crack extension. Looking at the fracture surfaces of these specimens, the presence of natural weld defects is observed (Fig. 10b). These natural defects contribute to the crack extension as measured by the nine point average method, though do not increase the potential drop across the crack during the test [25]. 


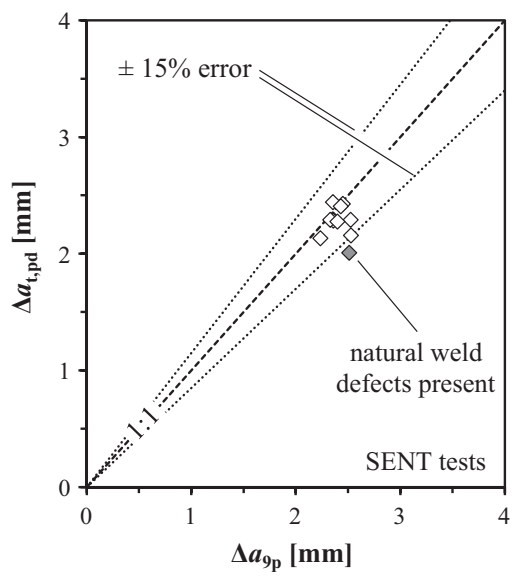

(a)

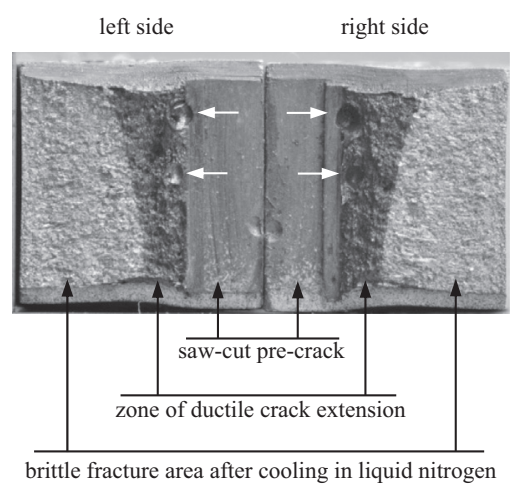

(b)

Fig. 10. Evaluation of the accuracy of the potential drop measurements on SENT specimens (a) with view on the cracked surface of specimen with natural weld defects (b).

\subsection{Effect of extraction position (o'clock variation)}

As previously noted, the test sets 2 and 3 defined in Section 2.2 sample material from the same girth weld. From the all weld metal tensile test specimens, a $24 \mathrm{MPa}(4 \%)$ difference in ultimate tensile strength was observed between specimens extracted from the 7 and 10 o'clock position.

For each set of SENT tests, the average tearing resistance curve and the width of the scatter band is determined (Fig. 11a). In addition, an average tearing resistance curve, considering all SENT data from the same girth weld, was determined with the corresponding scatter band. In the latter case, the width of the scatter band, $\delta_{s}$, was $0.16 \mathrm{~mm}$.

\subsection{Crack extension in MWP testing}

In contrast to the SENT specimens, the MWP specimens have not been broken up in a brittle way after completion of the test. As an alternative, macrographs have been made at the central cross section of the notched weld to evaluate the crack extension at the deepest point. By means of example, the potential drop measurements for the MWP specimen of set 5 are shown together with the force, strain and CMOD measurements (Fig. 12). The point of crack initiation, as predicted by the potential drop method (Fig. 12c), corresponds to the instant at which the CMOD increases more than linear with the remote strain. The latter is shown in Fig. 12b, where the strain evolution for both base materials is plotted as function of the CMOD. This also indicates the maximum strain capacity in both plates $\left(\varepsilon_{\max ; a}\right.$ and $\left.\varepsilon_{\text {max;b }}\right)$. The moment the CMOD increases more

\begin{tabular}{cccc}
\hline & $\boldsymbol{\delta}_{\boldsymbol{1}}$ & $\boldsymbol{\delta}_{\boldsymbol{2}}$ & $\boldsymbol{\delta}_{\boldsymbol{s}}$ \\
\hline SENT 2a & 1.11 & 0.35 & 0.14 \\
\hline SENT 2b & 1.09 & 0.39 & 0.12 \\
\hline SENT 3a & 1.18 & 0.44 & 0.15 \\
\hline SENT 3b & 1.14 & 0.38 & 0.16 \\
\hline all & $\mathbf{1 . 1 0}$ & $\mathbf{0 . 3 9}$ & $\mathbf{0 . 1 6}$ \\
\hline
\end{tabular}

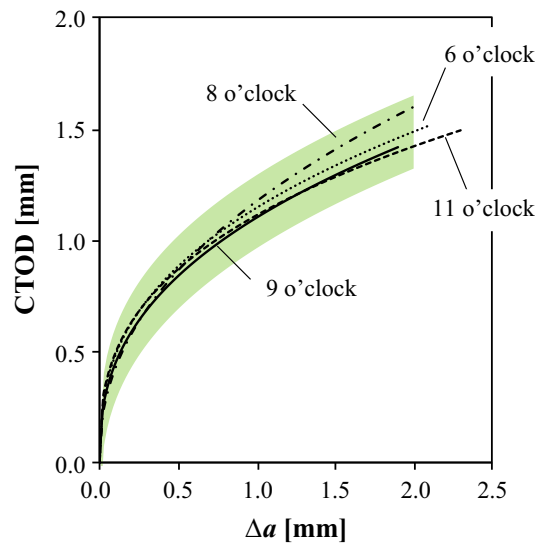

(a)

(b)

Fig. 11. Fitting parameters and width of scatter band for specimens extracted from same girth weld but different o'clock position (a) and resulting scatter band from global fit from all SENT test data obtained from set 2 and 3 together with fitted curves for distinct o'clock positions (b). 


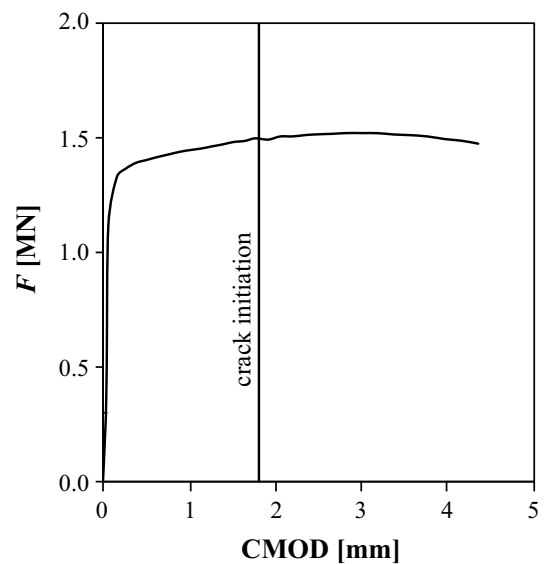

(a)

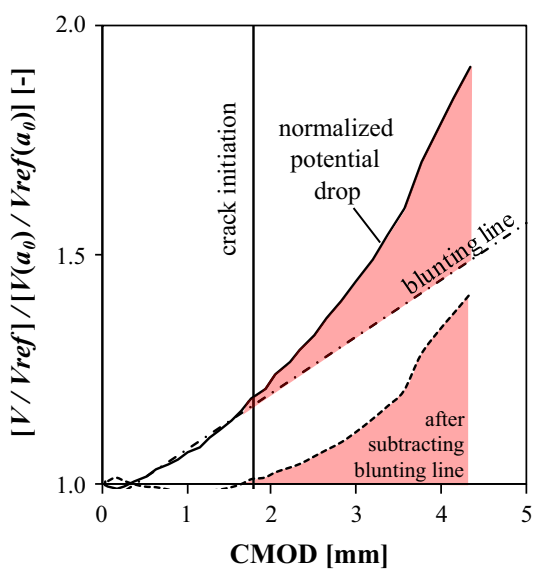

(c)

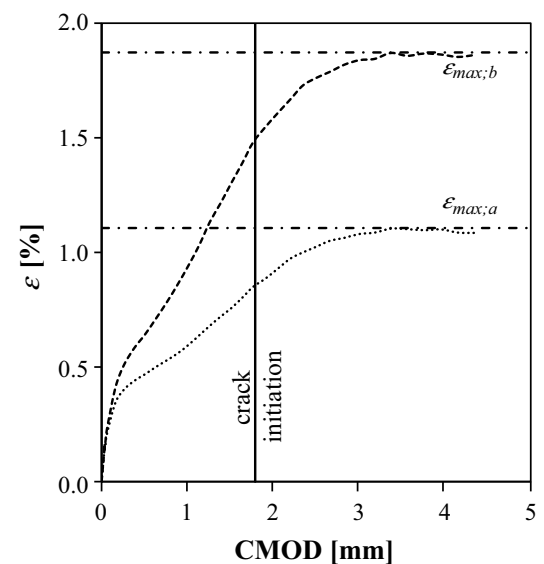

(b)

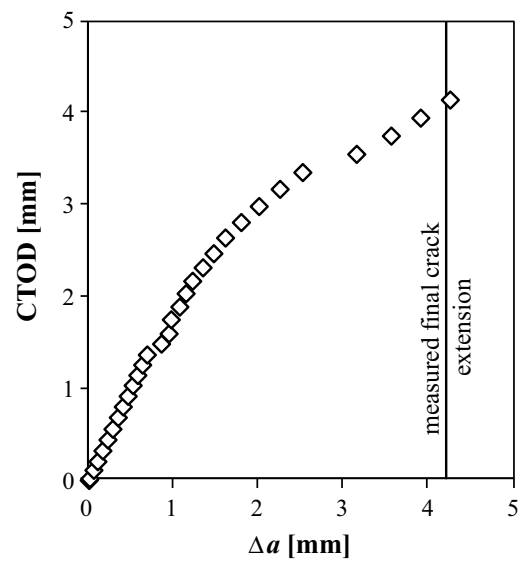

(d)

Fig. 12. Evaluation of ductile crack extension in specimen MWP5: force - CMOD diagram (a), remote strain - CMOD diagram (b), potential drop - CMOD diagram (c) and tearing resistance (d).

than linear is well before maximum force, as indicated in Fig. 12a. Fig. 12d shows the obtained resistance curve together with the measured final crack extension; an excellent agreement is observed.

Similar observations are made for the other specimens, though for some tests the amount of ductile crack extension is slightly underestimated (Fig. 13a). For one MWP specimen, going with set 3 , the crack extension is even largely underestimated. This is understood from the macrograph (Fig. 13b), in which a clear deviation of the crack path is observed. This deviation is most likely caused by the presence of a natural weld defect and might be additionally attributed to the weld strength overmatch [48]. The strain concentrates in the lower strength base metal at the left side, which directs the crack path towards this lower strength material. During the sectioning process for preparing the macrograph, it appeared furthermore that the crack extension did not take place along the entire length of the crack. Consequently, the assumptions made in the finite element model are violated; the crack extension produces a far from semi-elliptical crack front. It is clear that this test points out the limitations of the presented potential drop method.

\subsection{Comparison of tearing resistance curves}

Based on the potential drop measurements in combination with the double clip gauge CTOD measurements, a comparison can be made between the tearing resistance curves obtained from SENT and MWP testing. An overview of the fitting coefficients is provided in Table 2, representing the average curve in case of the SENT tests. Additionally, as an illustrative example, the tearing resistance curves for the specimens extracted from set 1 and 2 are shown in Fig. 14a and b respectively. Remark that the tearing resistance of the SENT specimens is not presented by a single line; instead the $95 \%$ confidence interval is shown that is obtained from the different tests extracted from the same material. 


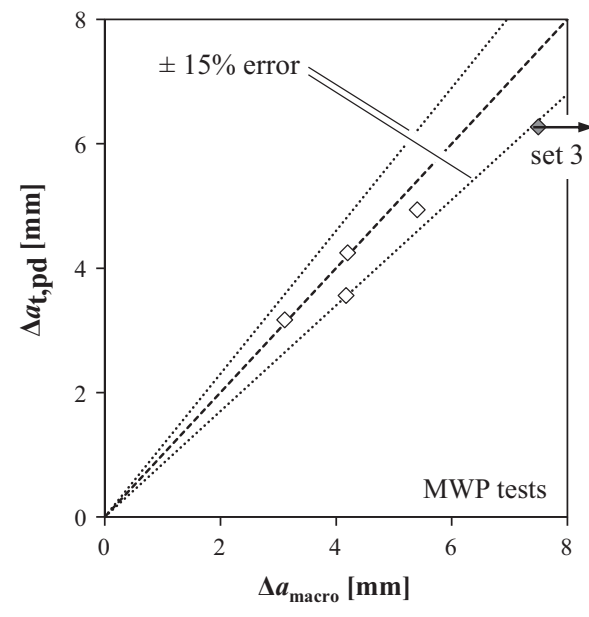

(a)

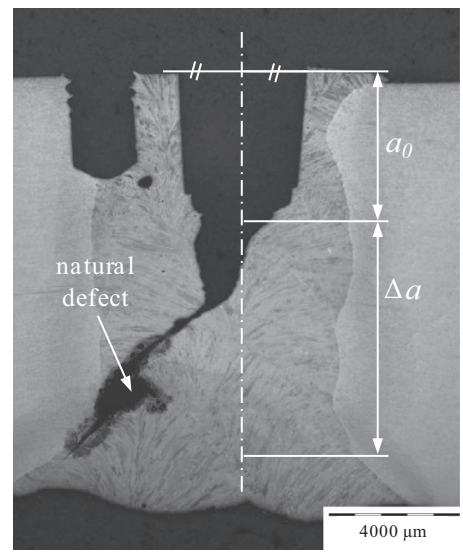

(b)

Fig. 13. Comparison between measured and predicted ductile crack extension for MWP tests (a) and macrograph taken after completion of test going with set 3 (b).

Table 2

Overview of curve fitting parameters for SENT and MWP tests from the same set.

\begin{tabular}{lllll}
\hline Set & \multicolumn{2}{l}{ SENT } & \multicolumn{2}{l}{ MWP } \\
\cline { 2 - 3 } & $\delta_{1}$ & $\delta_{2}$ & $\delta_{1}$ & $\delta_{2}$ \\
\hline 1 & 2.14 & 0.48 & 1.90 & 0.94 \\
2 & 1.10 & 0.37 & 1.61 & 0.64 \\
3 & 1.15 & 0.42 & 1.46 & 0.52 \\
4 & 1.32 & 0.46 & 1.54 & 0.58 \\
5 & 1.37 & 0.49 & 2.13 & 0.45 \\
\hline
\end{tabular}

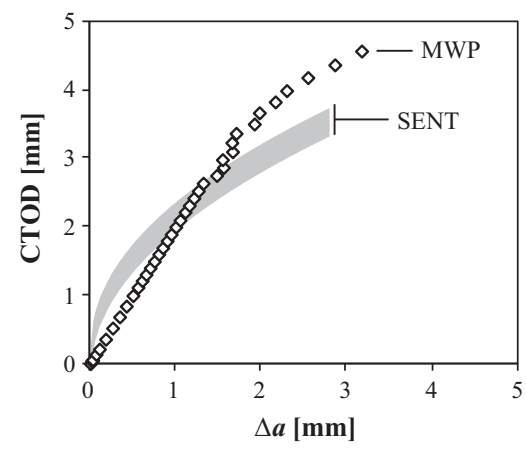

(a)

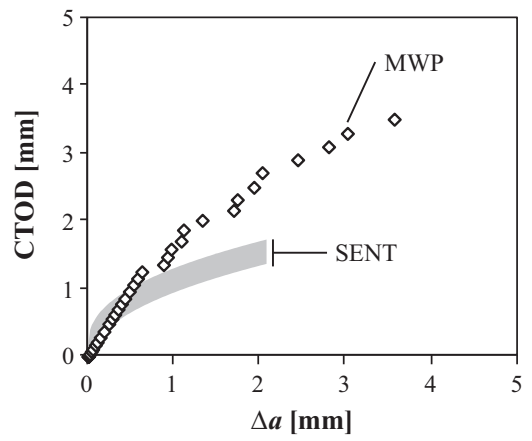

(b)

Fig. 14. Comparison of resistance curves obtained from non-welded (series 1) (a) and welded (series 2) (b) SENT and MWP specimens.

\section{Discussion}

From an extensive set of experiments, a difference in tearing resistance is observed between SENT and MWP specimens extracted from the same girth weld. In the previous section, i.e. Table 2, the difference between both specimens has been quantified. The measurement data unmistakably indicated that the tearing resistance for this MWP test exceeds that from the SENT tests data (Fig. 14a). 
There are various potential reasons for this observed difference in tearing resistance between MWP and SENT tests:

- Difference in crack depth: as already indicated in the methodology section (Section 2.1), it has been reported that the relative crack depth impacts the crack tip constraint and hence alter the tearing resistance. However, the current experimental program was set up in such way that the relative crack depth in SENT and wide plate specimens differed only marginally.

- Variability of material properties: Weld metal properties are not necessarily homogeneous around the pipe circumference. A pipe tested in the framework of this paper has for instance shown a noticeable difference in the weld metal strength properties (4\% difference in terms of tensile strength). Notwithstanding this variability, it has been demonstrated that the tearing resistance was hardly altered by the extraction position. In the contrary, the scatter in tearing resistance for specimens extracted around the pipe's circumference hardly differs from the scatter observed between specimens extracted adjacent to each other (i.e. at the same o'clock position). To furthermore reduce the impact of potential weld metal variation, the SENT specimens in the current test program were extracted symmetrically around the wide plate specimen. Accordingly, the potential variability was accounted for by comparing the wide plate results to the resulting scatter bands rather than individual curves. This again pointed out that the MWP curves exceeded the SENT curves.

- Crack path deviation: In a previous publication, Fairchild et al. have argued that the observed relationship might result from an overestimation of the tearing resistance in MWP specimens [49]. This could be attributed to an underestimation of the ductile crack extension for specimens that show a tilted (i.e. not in the plane of the original notch) crack extension. However, such crack extension was only observed for one specimen.

Considering the above arguments, it is believed that the observed difference in tearing resistance should be explained from a constraint point of view. In literature, several (numerical) studies indicate that the constraint in SENT specimens is comparable to pipe specimens $[14,50]$. Additionally considering the previously published correspondence in constraint between pipe and wide plate specimens [17], it was therefore expected for wide plate and SENT specimens to experience a similar constraint. A closer look to the published literature on SENT testing shows however that the correspondence in constraint is primarily observed for (extremely) shallow notch depths (typically $a_{0} / W=0.1$ ). For deeper cracks, it has been reported that SENT specimens become more conservative with respect to pipes [50,51]. As the relative crack depth in the current study ranges between 0.2 and 0.3 , it is thus not surprising that the SENT specimens yield lower tearing resistance curves compared to the wide plate specimens. A second reason that furthermore lowers the tearing resistance in the SENT specimens, is the presence of side grooves. These locally increase the constraint and promote crack extension [24]. The latter is additionally supported by the constraint calculations provided in Annex $\mathrm{N}$ of the recently updated BS7910:2013 [52].

Summarized, in view of girth weld defect assessment procedures, SENT testing still introduces a significant amount of conservatism. This potentially reduces the allowable defect dimensions. Consequently, for defects that are not acceptable after an assessment based on SENT results, wide plate testing might be seen as a potential higher-level alternative, closely matching the in-service conditions. One should take into account the increased complexity of analyzing wide plate tests as expertise is needed for both experimental work and numerical work (in this study: calibration of DCPD response through finite element modeling).

\section{Conclusion}

To evaluate the difference in tearing resistance obtained from wide plate and SENT specimens extracted from the same material, an extensive test program has been performed. The results of this test program have indicated that:

- Direct Current Potential Drop (DCPD) measurements are suitable to evaluate the ductile crack extension both for SENT and wide plate specimens.

- The tearing resistance for wide plate specimens exceeds the tearing resistance obtained from SENT testing for the same material.

- The variability of the tearing resistance as function of the o'clock position might be limited despite remarkable differences in tensile strain properties.

\section{Acknowledgements}

The authors would like to acknowledge the financial support of the IWT (Agency for Innovation by Science and Technology - Grant Nos. SB-091512 and SB-093512) and the FWO (Research Foundation Flanders - Grant Nos. 1.1.880.09.N.00 and 1.1.880.11.N.01). 


\section{References}

[1] Fairchild DP et al. A multi-tiered procedure for engineering critical assessment of strain-based pipelines. In: International offshore and polar engineering conference. Maui (HI, United States); 2011.

[2] Wang YY et al. Multi-tier tensile strain models for strain-based design - Part 1: Fundamental basis. In: International pipeline conference. Calgary, Alberta, Canada; 2012. p. IPC2012-90690.

[3] Denys R et al. Strain capacity prediction for strain-based pipeline designs. In: International workshop on welding of high strength pipeline steels. Araxá, Brazil; 2011.

[4] Denys R, Lefevre AA. UGent guidelines for curved wide plate testing. In: Pipeline technology conference. Ostend, Belgium; 2009. p. Ostend2009-110.

[5] Hertelé $S$ et al. Curved Wide Plate testing with advanced instrumentation and interpretation. In: International pipeline conference. Calgary, Alberta, Canada; 2012. p. IPC2012-90591.

[6] Shen G, Gianetto JA, Tyson WR. Measurement of J-R curves using single specimen technique on clamped SE(T) specimens. In: International offshore and polar engineering conference. Osaka, Japan; 2009.

[7] Cravero S, Ruggieri C. Correlation of fracture behavior in high pressure pipelines with axial flaws using constraint designed test specimens - Part I: Plane strain analysis. Engng Fract Mech 2005;72:1344-60.

[8] Verstraete $\mathrm{M}$ et al. Pressure correction factor for strain capacity predictions based on Curved Wide Plate testing. In: International pipeline conference. Calgary, Canada; 2012.

[9] Fairchild DP et al. Continued advancements regarding capacity prediction of strain-based pipelines. In: International pipeline conference. Calgary, Alberta, Canada; 2012. p. IPC2012-90471.

[10] DNV. RP-F108: fracture control for pipeline installation methods introducing cyclic plastic strain. Det Norske Veritas; 2006.

[11] Cravero S, Ruggieri C. Estimation procedure of J-resistance curves for SE(T) fracture specimens using unloading compliance. Engng Fract Mech 2007;74:2735-57.

[12] Verstraete MA, Hertelé S, Denys RM, Van Minnebruggen K, De Waele W. Evaluation and interpretation of ductile crack extension in SENT specimens using unloading compliance technique. Engng Fract Mech 2014;115:190-203.

[13] Tang H et al. Development of the SENT test for strain-based design of welded pipelines. In: International pipeline conference. Calgary, Alberta, Canada; 2010. p. IPC2010-31590.

[14] Cravero S, Bravo RE, Ernst HA. Constraint evaluation and effects on J-R resistance curves for pipes under combined load conditions. In: International offshore and polar engineering conference. Vancouver, British Columbia, Canada; 2008.

[15] Nourpanah N, Taheri F. A numerical study on the crack tip constraint of pipelines subject to extreme plastic bending. Engng Fract Mech 2011;78:1201-17.

[16] Silva LAL, Cravero S, Ruggieri C. Correlation of fracture behavior in high pressure pipelines with axial flaws using constraint designed test specimens Part II: 3D effects on constraint. Engng Fract Mech 2006;73:2123-38.

[17] Verstraete MA, De Waele W, Denys RM, Van Minnebruggen K, Hertelé S. Constraint analysis of defects in strength mismatched girth welds of (pressurized) pipe and curved wide plate tensile test specimens. Engng Fract Mech 2014. http://dx.doi.org/10.1016/i.engfracmech.2014.07.018.

[18] Cheng W et al. Test methods for characterization of strain capacity: comparison of R-curves from SENT/CWP/FS tests. In: Denys RM, editor. Editor pipeline technology conference. Ostend, Belgium; 2009. p. Ostend 2009-040.

[19] Wang YY et al. Second generation models for strain-based design. Houston (Texas, United States): Pipeline Research Council International; 2011.

[20] Wang E et al. An experimental study on J(CTOD)-R curves of single edge tension specimens for X80 steel. In: International pipeline conference. Calgary, Alberta, Canada; 2012. p. IPC2012-90323.

[21] Thaulow C et al. Constraint correction of high strength steel - selection of test specimens and application of direct calculations. Engng Fract Mech 2004;71:2417-33.

[22] Hertelé S et al. Applications of digital image correlation in girth weld testing. In: Pipeline technology conference. Ostend, Belgium; 2013.

[23] Hertelé $\mathrm{S}$ et al. Investigation of strain measurements in (curved) wide plate specimens using digital image correlation and finite element analysis. J Strain Anal Engng Des 2012;47(5):276-88.

[24] Shen G et al. Effect of side grooves on compliance, J-integral and constraint of clamped SE(T) specimen. In: Pressure vessels and piping conference. Bellevue (Washington, USA); 2010. p. PVP2010-25164.

[25] Verstraete M et al. Single-specimen evaluation of tearing resistance in SENT testing. Engng Fract Mech 2014, submitted for publication.

[26] Hertelé $S$ et al. Weld strength mismatch in strain based flaw assessment: which definition to use? J Pressure Vessel Technol 2013;135:1-8.

[27] Denys R. Testing for weld metal yield strength. Mis-matching of welds - ESIS17; 1994. p. 777-87.

[28] Swankie T et al. Evaluation of girth weld defect acceptance criteria for grade X100 pipelines. In: International pipeline conference. Calgary, Alberta, Canada; 2012.

[29] Ostby E et al. The effects of weld metal mismatch and crack position on the strain capacity in SENT specimens in an X65 material. In: International offshore and polar engineering conference. Osaka, Japan; 2009.

[30] Hertelé S et al. Weld strength mismatch in strain based flaw assessment: which definition to use? In: Pressure vessels and piping conference. Toronto, Canada; 2012. p. PVP2012-78306.

[31] ASTM. E1820 - standard test method for measurement of fracture toughness. American Society of Testing and Materials; 2011.

[32] Cerny I. The use of DCPD method for the measurement of growth of cracks in large components at normal and elevated temperatures. Engng Fract Mech 2004;71:837-48.

[33] Yee R, Lambert SB. A reversing direct current potential drop system for detecting and sizing fatigue cracks along weld toes. J Test Eval $1995 ; 23(4): 254-60$

[34] Lloyd WR, Reuter WG, Weinberg DM. Crack growth monitoring in harsh environments by electrical potential measurements. In: Harsh environment sensors II. Boston (MA, USA); 1999. p. INEEL/CON-99-00889.

[35] Merah N. DC potential drop calibration in creep-fatigue loading conditions. J Test Eval 2000;28(4):301-6.

[36] Doig P, Abbott KR. Single specimen fracture toughness testing of low strength steel plate using the direct current electrical potential method. J Test Eval 1984;12(5):297-304.

[37] Chipperfield CG. Detection and toughness characterisation of ductile crack initiation in 316 stainless steel. Int J Fract 1976 ; $12(6)$ :873-86.

[38] Srawley JE, Brown WFJ. Fracture toughness testing. Cleveland (OH, USA): National Aeronautics and Space Administration, NASA; 1965.

[39] Wilkowski G, Wambaugh JO, Prabhat K. Single specimen J-resistance curve evaluations using the DC electric potential method and a computerized data acquisition system. In: Fracture mechanics: fifteenth national symposium; 1982. p. 553-78.

[40] Verstraete M. Experimental-numerical evaluation of ductile tearing resistance and tensile strain capacity of biaxially loaded pipelines. In: Soete Laboratory, Ghent University; 2013.

[41] Johnson HH. Calibrating the electric potential method for studying slow crack growth. Mater Res Stand 1965:442-5.

[42] Cadario A, Alfredsson B. Fatigue growth of short cracks in Ti-17: experiments and simulations. Engng Fract Mech 2007;74:2293-310.

[43] Denys R, Lefevre AA. Failure characterization of a girth weld with surface-breaking flaw under tensile load. In: Pipeline technology conference. Ostend (Belgium); 2009. p. Ostend2009-111.

[44] Ohata $\mathrm{M}$ et al. Prediction of tensile strain limit for leak of high pressure pipe with surface crack. In: Pipeline technology conference. Ostend, Belgium; 2009. p. Ostend2009-0065.

[45] Hertelé S et al. Parametric finite element model for large scale tension tests on flawed pipeline girth welds. Adv Engng Softw 2012;47(1):24-34.

[46] Landes JD. The blunting line in elastic-plastic fracture. Fatigue Fract Engng Mater Struct 1995;18(11):1289-97. 
[47] Verstraete M et al. Determination of tearing resistance in SENT and CWP specimens using direct current potential drop measurements. In: Pipeline technology conference. Ostend, Belgium; 2013.

[48] Denys R et al. Material tensile properties in relation to the failure behavior of girth welds subject to plastic longitudinal strains. In: Proceedings of the international conference on application and evaluation of high-grade pipelines in hostile environments. Yokohama, Japan; 2002 . p. 159-72.

[49] Fairchild DP et al. Girth Welds for Strain-based design pipelines. In: International offshore and polar engineering conference. Vancouver, Canada; 2008.

[50] Xu J et al. Constraint effect on the ductile crack growth resistance of circumferentially cracked pipes. Engng Fract Mech 2010;77:671-84.

[51] Cravero S, Ruggieri C. Integrity assessment of pipelines using SE(T) specimens. In: International pipeline conference. Calgary, Alberta, Canada; 2004. p. IPC04-0033.

[52] BS7910. Guide to methods for assessing the acceptability of flaws in metallic structures. In: Annex N - allowance for constraint effects; 2013. 